\title{
An Electrochemical Impedance Spectroscopy Study on the Effects of the Surface- and Solution-Based Mechanisms in Li-O2Cells
}

\author{
Knudsen, Kristian Bastholm; Vegge, Tejs; McCloskey, Bryan D.; Hjelm, Johan
}

Published in:

Journal of the Electrochemical Society

Link to article, DOI:

10.1149/2.1111609jes

Publication date:

2016

Document Version

Publisher's PDF, also known as Version of record

Link back to DTU Orbit

Citation (APA):

Knudsen, K. B., Vegge, T., McCloskey, B. D., \& Hjelm, J. (2016). An Electrochemical Impedance Spectroscopy Study on the Effects of the Surface- and Solution-Based Mechanisms in Li-O Cells. Journal of the

Electrochemical Society, 163(9), A2065-A2071. https://doi.org/10.1149/2.1114609jes

\section{General rights}

Copyright and moral rights for the publications made accessible in the public portal are retained by the authors and/or other copyright owners and it is a condition of accessing publications that users recognise and abide by the legal requirements associated with these rights.

- Users may download and print one copy of any publication from the public portal for the purpose of private study or research.

- You may not further distribute the material or use it for any profit-making activity or commercial gain

- You may freely distribute the URL identifying the publication in the public portal 


\title{
An Electrochemical Impedance Spectroscopy Study on the Effects of the Surface- and Solution-Based Mechanisms in $\mathrm{Li}-\mathrm{O}_{2}$ Cells
}

\author{
Kristian B. Knudsen, ${ }^{a, b, *}$ Tejs Vegge, ${ }^{a}$ Bryan D. McCloskey, ${ }^{\mathbf{b}, c, *, z}$ and Johan Hjelm ${ }^{\mathrm{a}, *, \mathrm{z}}$ \\ ${ }^{a}$ Department of Energy Conversion and Storage, Technical University of Denmark, 4000 Roskilde, Denmark \\ ${ }^{b}$ Department of Chemical and Biomolecular Engineering, University of California, Berkeley, California 94720, USA \\ ${ }^{c}$ Energy Storage and Distributed Resources Division, Lawrence Berkeley National Laboratory, Berkeley, California \\ 94720, USA
}

\begin{abstract}
The maximum discharge capacity in non-aqueous $\mathrm{Li}_{-} \mathrm{O}_{2}$ batteries has been limited to a fraction of its theoretical value, largely due to a conformal deposition of $\mathrm{Li}_{2} \mathrm{O}_{2}$ on the cathode surface. However, it has recently been established that additives that increase the shielding of either $\mathrm{O}_{2}{ }^{-}$or $\mathrm{Li}^{+}$will activate the formation of toroidal shaped $\mathrm{Li}_{2} \mathrm{O}_{2}$, thereby dramatically increasing cell capacity. Here we apply porous electrode theory to electrochemical impedance measured at the $\mathrm{Li}-\mathrm{O}_{2}$ cathode to investigate changes in the surface- and ionic resistance within the pores under conditions where either the surface-mechanism or the solution-mechanism is favored. Our experimental observations show that (i) an additional charge transfer process is observed in the impedance spectrum where the solution-based mechanism is favored; (ii) that the changes in the ionic resistance in the cathode during discharge (related to $\mathrm{Li}_{2} \mathrm{O}_{2}$ build up) is much greater in cells where the solution-based mechanism is activated and can qualitatively determine the extent of discharge product deposited within the pores of the cathode versus the deposition extent at the electrode/electrolyte interface; and (iii) that the observed "sudden-death" during discharge is a consequence of the increasing charge transfer resistance regardless of whether $\mathrm{Li}_{2} \mathrm{O}_{2}$ forms predominantly through either the surface- or solution-based mechanism.

(C) The Author(s) 2016. Published by ECS. This is an open access article distributed under the terms of the Creative Commons Attribution 4.0 License (CC BY, http://creativecommons.org/licenses/by/4.0/), which permits unrestricted reuse of the work in any medium, provided the original work is properly cited. [DOI: 10.1149/2.1111609jes] All rights reserved.
\end{abstract}

Manuscript received June 14, 2016. Published July 23, 2016.

The Li- $\mathrm{O}_{2}$ battery has, since Jiang and Abraham's seminal 1996 report, ${ }^{1}$ received significant attention due to its high theoretical specific energy and energy density of $3500 \mathrm{Wh} / \mathrm{kg}$ and $3400 \mathrm{Wh} / \mathrm{L}$, respectively. ${ }^{2}$ These values are based on the overall cell reaction in non-aqueous electrolytes that can be described as $2 \mathrm{Li}+\mathrm{O}_{2} \leftrightarrows$ $\mathrm{Li}_{2} \mathrm{O}_{2}$, with the forward reaction corresponding to discharge and the reverse direction to charge. To understand how to more appropriately engineer a practical $\mathrm{Li}-\mathrm{O}_{2}$ cathode and electrolyte, the mechanism of $\mathrm{Li}_{2} \mathrm{O}_{2}$ formation has been the focus of significant research in the past 10 years. Laorie et al. ${ }^{3,4}$ initially showed that varying Lewis basicity of the electrolyte substantially influenced the electrochemical kinetics and reversibility of the $\mathrm{Li} / \mathrm{O}_{2}$ reaction. Deposition morphology of $\mathrm{Li}_{2} \mathrm{O}_{2}$ was also found to be influenced by electrolyte properties ${ }^{5}$ and current density ${ }^{6,7}$ with large $(\sim 500-1000 \mathrm{~nm})$ toroids or thin $(\sim 5 \mathrm{~nm})$ conformal films of $\mathrm{Li}_{2} \mathrm{O}_{2}$ forming under various conditions. These observations have been explained by two independent reaction mechanisms that appear to be influenced primarily by electrolyte Lewis acidity or basicity, ${ }^{5,8,9}$ which can be tuned through solvent, ${ }^{5}$ anion, ${ }^{9}$ and additive ${ }^{8}$ selection.

These two main reaction pathways for $\mathrm{Li}_{2} \mathrm{O}_{2}$ deposition are referred to here as either the surface- or solution-based mechanism. The surface mechanism (Figure 1a) occurs in electrolytes with low Lewis basicity and acidity, where $\mathrm{LiO}_{2}$ is insoluble, disallowing diffusion away from its initial site of formation and resulting in conformal $\mathrm{Li}_{2} \mathrm{O}_{2}$ film formation during discharge. ${ }^{10-12}$ Given that $\mathrm{Li}_{2} \mathrm{O}_{2}$ is an electronic insulator and insoluble in organic aprotic solvents regardless of their acid/base character, ${ }^{2}$ this conformal deposition leads to relatively fast passivation of the electrode surface, limiting the ultimate discharge capacity of the cell. In contrast, in electrolytes with high Lewis acidity/basicity, $\mathrm{LiO}_{2}$ 's solubility is greater, thereby allowing diffusion of solvated $\mathrm{O}_{2}{ }^{-}$away from the cathode, where it ultimately undergoes disproportionation on a growing $\mathrm{Li}_{2} \mathrm{O}_{2}$ toroid. This solution-based mechanism (Figure $1 b$ ) can circumvent issues related to $\mathrm{Li}_{2} \mathrm{O}_{2}$-induced electronic insulation of the cathode, resulting in discharge capacities that are substantially (sometimes approaching an order of magnitude) higher than can be obtained when the surface-based mechanism dominates.
Højberg et al. ${ }^{13}$ used in-operando electrochemical impedance spectroscopy to link charge transfer limitations to capacity limitations in cells employing a low Lewis acidic/basic electrolyte (lithium bis-(trifluoromethyl sulfonyl) imide (LiTFSI) as a salt and 1,2dimethoxyethane (DME) as the solvent), where the surface mechanism of $\mathrm{Li}_{2} \mathrm{O}_{2}$ formation is dominant. However, the mode of cell failure is not known when the solution mechanism is dominant and could be related to pore clogging, $\mathrm{O}_{2}$ diffusion limitations, or electronic passivation. In this paper, we utilize three-electrode $\mathrm{Li}-\mathrm{O}_{2}$ cells to separate the total cell impedance into separate contributions from the cathode and anode during galvanostatic discharges. A conventional porous electrode model was used to parameterize the impedance of the porous carbon cathode. This allows characterization of the surface impedance and thus the charge transfer resistance of the oxygen reduction reaction, along with the ionic conductivity inside the pores of the electrode (a proxy for pore clogging resistance), which was studied as a function of the electrolyte composition, varied to induce the solution mechanism. We observe an additional faradaic process in cells where the solution mechanism is dominant, specifically, those which have a minor water impurity (a highly Lewis acidic additive) or have an anion $\left(\mathrm{NO}_{3}{ }^{-}\right)$with sufficiently high Lewis basicity to induce the solution mechanism. Lastly, we comment on the capacity limiting processes of each system, which we find in all cases is linked to charge transfer resistance increases as a result of $\mathrm{Li}_{2} \mathrm{O}_{2}$ deposition at the cathode/electrolyte interface.
Surface mechanism

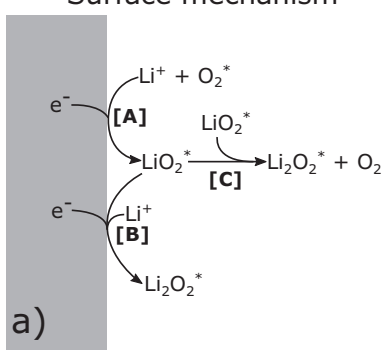

Solution-based mechanism

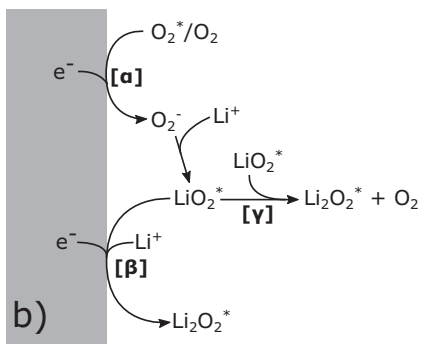

Figure 1. Schematic of the two $\mathrm{O}_{2}$ reduction mechanisms. In a) the surfacebased mechanism is depicted while the solution-based mechanism is shown in b). Species marked with $(*)$ refers to an adsorbed specie on the cathode surface. 


\section{Porous Electrode Theory}

The impedance model that describes an electronically conducting porous electrode immersed and filled with a liquid electrolyte is known as porous electrode theory (PET) and was first developed by de Levie and Delahay. ${ }^{14}$ The porous electrode is modeled as a cylindrical pore containing electrolyte where the pore wall corresponds to the surface of the solid conducting electrode. This type of impedance model has frequently been used e.g. to describe ideally polarizable porous gold- and nickel-based electrodes, ${ }^{15-17}$ composite solid state fuel cell electrodes,${ }^{18,19}$ super capacitors, ${ }^{20,21}$ Li-ion batteries, ${ }^{22-25}$ nano-porous $\mathrm{TiO}_{2}$ electrodes, ${ }^{26,27}$ and conducting polymer electrodes. ${ }^{28,29}$

The impedance of porous electrodes depends on the pore geometry, pore size distribution, the presence and concentration of redox species, and can be further complicated by the presence of potential and concentration gradients within the pores that may arise when a dc current is applied. In the absence of faradaic reactions, only doublelayer charging takes place and the surface impedance can be modeled with a capacitor or more generally with a constant phase element. When faradaic reactions occur, the surface impedance must include a charge transfer resistance connected in parallel with the capacitive element modeling the double-layer charging. For more complex situations, such as with ion intercalation into the electrode particles, one or more additional impedance elements need to be included in the surface impedance, e.g. a finite space Warburg diffusion element to model diffusion of guest ions inside the active particles. Furthermore, the presence of significant potential or concentration gradients can complicate the resulting porous electrode impedance, but here (as discussed below) we have interpreted the impedance using a model neglecting such effects, which may over-estimate the double-layer capacitance of the porous electrode somewhat. ${ }^{30}$ The porous electrode model can be described by a general transmission line model ${ }^{29,31}$ represented by Eqs. 1-2.

$$
Z_{\text {tot }}=\frac{\mathrm{X}_{1} \cdot \mathrm{X}_{2}}{\mathrm{X}_{1}+\mathrm{X}_{2}} \cdot\left(L+\frac{2 \lambda}{\sinh \left(\frac{L}{\lambda}\right)}\right)+\lambda \cdot \frac{\mathrm{X}_{1}^{2}+\mathrm{X}_{2}^{2}}{\mathrm{X}_{1}+\mathrm{X}_{2}} \cdot \operatorname{coth}\left(\frac{L}{\lambda}\right)
$$

with

$$
\lambda=\sqrt{\frac{\zeta}{X_{1}+X_{2}}}
$$

Here, $\lambda$ is the characteristic a.c. penetration depth [cm], which is equivalent to the electrochemical utilization thickness of the electrode, and $\mathrm{L}$ is the thickness of the electrode [cm], which is usually determined from cross sectional micrographs of the electrode (ignoring tortuosity of the percolating phases). Eq. 1 represents the impedance model of a single pore as illustrated in Figure 2.

$\mathrm{X}_{1}$ and $\mathrm{X}_{2}$ describe the resistance per unit length of (ionic or electronic) transport channels in the liquid and electrode, respectively. $\zeta$ is the surface impedance of the pore walls, e.g. the exchange of electrical charge at the surface related to faradaic reactions at the electrode $[\Omega \cdot \mathrm{cm}]$ in parallel with the double-layer charging process $[\mathrm{F} / \mathrm{cm}]$. Eqs. $1-2$ in principle describe the impedance of a single pore, however the porous electrode consists of $n$ columns per unit area. Although the number $n$ is difficult to obtain, a convenient and equally informative approach is to consider the porous electrode as one column, as it is depicted in Figure 2. This enables Eqs. 1-2 to be simplified to Eqs. 3-5 by also considering that practical carbon electrodes have an electronic conductivity that is much greater than that of the electrolyte's ionic conductivity, i.e. $\mathrm{X}_{2} \ll \mathrm{X}_{1}$ :

$$
Z_{t o t}=\lambda \cdot \mathrm{X}_{1} \cdot \operatorname{coth}\left(\frac{L}{\lambda}\right)
$$

with

$$
\lambda=\sqrt{\frac{\zeta}{\mathrm{X}_{1}}}
$$

Where $\lambda$ is the ac penetration depth [cm]. Then, the transport of ions in the flooded pores can be modeled as the resistance per unit length

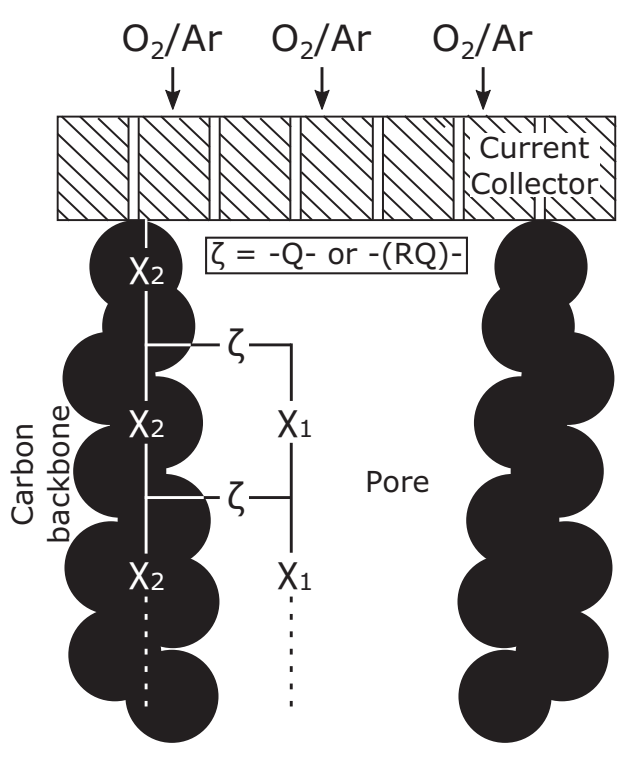

Figure 2. A schematic representation of the equivalent circuit that describes the porous electrode theory using to model the cathodic measured impedance where $\zeta$ is the equivalent circuit -Q- or -(RQ)- that describes the surface reaction at the pore walls of the cathode at either OCV or during discharge, respectively. $X_{1}$ and $X_{2}$ describes the transport channels of the liquid and the conducting electrode, respectively.

of the electrode $[\Omega \cdot \mathrm{cm}]$ - i.e. the ionic resistance $\mathrm{R}_{\mathrm{i}}$.

$$
\mathrm{X}_{1}=R_{i}^{\prime}
$$

The surface impedance, $\zeta$, of the flooded pores will (i) in the absence of faradaic reactions, be modeled as a constant phase element, Q, to describe double layer charging, and (ii) in the presence of faradaic reactions (with $\mathrm{O}_{2}$ present in the electrolyte), be modeled as a parallel combination of a charge transfer resistance, $\mathrm{R}_{\mathrm{CT}}$, and a constant phase element in parallel, as depicted in Figure 2. $\zeta$ is then described by Eqs. 6 and 7 , for case (i) and (ii), respectively.

$$
\zeta_{Q}=\frac{1}{Q^{\prime} \cdot(j \omega)^{n}}
$$

and

$$
\zeta_{R Q}=\frac{R_{C T}^{\prime}}{1+R_{C T}^{\prime} \cdot Q^{\prime}(j \omega)^{n}}
$$

The shape of the impedance of the flooded porous electrode gives valuable insight into the balance between the resistance of the electrolyte in the pores and the pore surface impedance. To demonstrate this; simulations of the impedance spectra for selected key cases using either Eqs. 6 or 7 are shown in Figure 3. The impedance simulations depicted in Figures $3 \mathrm{a}-3 \mathrm{~b}$ illustrate the shape of the impedance in absence of faradaic reactions. Here, a characteristic high frequency linear region is observed, occurring due to the ionic resistance $\left(\mathrm{R}_{\mathrm{i}}\right)$ within the porous structure and as pointed out by Lasia and others ${ }^{15,30,32}$ this is the simplest experimental method to confirm whether an electrode displays any porous impedance character.

Figures $3 \mathrm{c}-3 \mathrm{~d}$ illustrates the shape of the impedance in the presence of a faradaic surface reaction similar to the equivalent circuit within the porous cathode in Figure 2. Here four situations are depicted where the ac penetration depth $(\lambda)$ starts with being much smaller than the thickness of the electrode $(\lambda \ll L)$, to being equal $(\lambda \sim L)$, and where lambda is much greater $(\lambda \gg L)$. As $\lambda$ is smaller or equal to the thickness of the electrode, a skewed semi-circle forms in the complex-plane as the impedance is dominated by the ionic resistance, $\mathrm{R}_{\mathrm{i}}$. As $\lambda$ increases, the complex semicircle becomes more ideal as the surface reaction on the pore wall starts to dominate the spectra. 

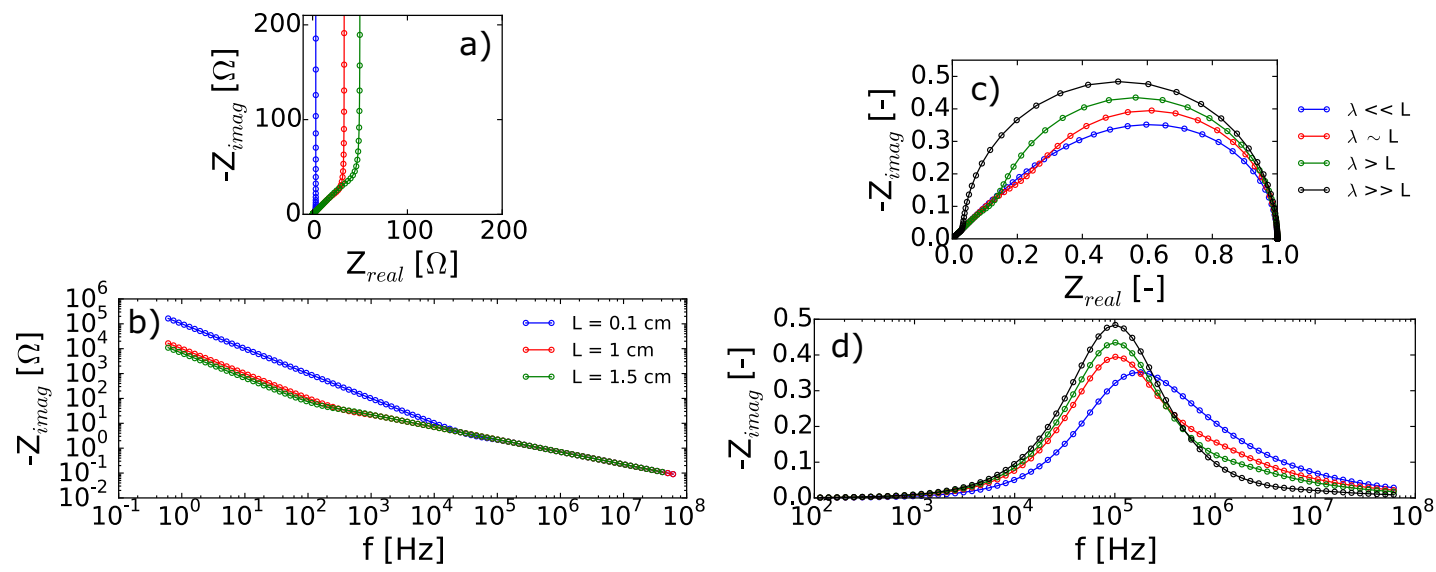

Figure 3. Impedance simulations of the PET model using two equivalent circuit elements: -Q- in (a-b) and -RQ- in (c-d). A Nyquist and Bode plot is shown for each system in ( $a$ and c) and ( $b$ and d), respectively. The simulations for (a-b) were performed by varying $\mathrm{L}$ to $0.1,1$, and $1.5 \mathrm{~cm}$ while $\mathrm{R}_{\mathrm{i}}, \mathrm{Q}$, and $\mathrm{n}$ were kept at $100 \Omega / \mathrm{cm}, 100 \mu \mathrm{F} / \mathrm{cm}$, and 1 , respectively. The simulations for (c-d) were performed by varying $\mathrm{R}_{\mathrm{i}}$ to $100,10,5$, and $1 \Omega / \mathrm{cm}$, while $\mathrm{R}_{\mathrm{CT}}, \mathrm{L}, \mathrm{Q}$, and $\mathrm{n}$ were constant at $0.1 \Omega \cdot \mathrm{cm}, 0.1 \mathrm{~cm}, 100 \mu \mathrm{F} / \mathrm{cm}$, and 1 , respectively.

\section{Experimental}

Cell assembly.- $-\mathrm{Li}-\mathrm{O}_{2}$ cells were assembled in three-electrode EL-air cells (EL-cell), which were modified with stainless steel inand outlets that replaced manufacturer supplied PEEK capillaries that are permeable toward $\mathrm{H}_{2} \mathrm{O}$. XC72 carbon black (Vulcan XC72, Cabotcorp, GA) or AvCarb P50 carbon paper (Fuelcellstore) was used as cathodes. The XC72 carbon cathodes (diameter $18 \mathrm{~mm}$ ) were manufactured by air-spraying a slurry of XC72 carbon black and PTFE in a wt/wt ratio of 3:1 in a 60:40 V/V ratio of water and isopropanol onto a T316 stainless 120 steel mesh (TWP Inc.). Typical combined loadings of XC72 and PTFE were $5.8 \mathrm{mg} / \mathrm{cm}^{2}$ of geometrical stainless steel mesh area. A number of electrolytes were used: $1 \mathrm{M}$ LiTFSI (BASF), 0.3/0.7 M LiTFSI/LiNO 3 (BASF), and $1 \mathrm{M}$ LiTFSI-1000 ppm $\mathrm{H}_{2} \mathrm{O}$, all in 1,2-dimethoxyethane (DME, BASF). Cells were assembled using a $16 \mathrm{~mm}$ lithium counter electrode (CE), a Li reference electrode (FMC), which was inserted into the cell house using a ECCRefload (EL-cell), then nine pieces of stacked Whatman QM-A glass fiber separators (VWR) was added following $400 \mu L$ of electrolyte and a disk cathode $(18 \mathrm{~mm})$. A sketch of the electrode positioning is presented in Figure S1. Cathodes and separators were washed three consecutive times in isopropanol and acetone before being dried in a heated antechamber attached to a glove box under vacuum at $110^{\circ} \mathrm{C}$ for $12 \mathrm{hrs}$. Cell assembly and electrolyte preparation were carried out in an Ar-filled glove box with $<0.1 \mathrm{ppm} \mathrm{O}_{2}$ and $<0.1 \mathrm{ppm} \mathrm{H}_{2} \mathrm{O}$. The BET surface area of the XC72 was determined to be $235 \mathrm{~cm}^{2} / \mathrm{mg}$.

Non-porous planar electrode experiments.-The $\mathrm{Li}^{-} \mathrm{O}_{2}$ electrochemistry was also characterized on planar, nonporous, glassy-carbon (GC) PEEK shrouded disk working electrodes $(\mathrm{d}=1.6 \mathrm{~mm}$, BioLogic) in a glass cell containing $1 \mathrm{M}$ LiTFSI-DME. The measurements were carried out in a three-electrode setup with a Pt CE and a dual-RE consisting of a double junction $\mathrm{Ag} / 0.01 \mathrm{M} \mathrm{AgNO}_{3}-1 \mathrm{M}$ LiTFSI-DME// $1 \mathrm{M}$ LiTFSI-DME// in parallel with a $0.1 \mu \mathrm{F}$ capacitor connected to a second Pt wire in solution. This RE made it possible to obtain high quality electrochemical impedance measurements at high ( $\mathrm{f}>\sim 100 \mathrm{~Hz}$ ) frequencies; similar RE have previously been reported $^{30,33,34}$. This setup is described in detail in Knudsen et al. ${ }^{10}$

Electrochemical measurements.-Electrochemical measurements were performed using Bio-Logic VMP3 or VSP potentiostats. Electrochemical impedance spectroscopy (EIS) was performed potentiostatically at OCV using an ac amplitude of $10 \mathrm{mV}$ in the frequency range $100 \mathrm{kHz}$ to $50 \mathrm{mHz}$ with 9 points/decade and 10 cycles/frequency. EIS was also performed galvanostatically during discharge using a dc current of $400 \mu \mathrm{A} / \mathrm{cm}^{2}$ and an ac amplitude of $40 \mu \mathrm{A} / \mathrm{cm}^{2}$ in the frequency range $100 \mathrm{kHz}$ to $10 \mathrm{mHz}$ with 9 points/decade and 2 cycles/frequency and a lower cutoff cell potential of $2 \mathrm{~V}$ vs. $\mathrm{Li}^{0 /+}$. The quality of the acquired EIS spectra were evaluated by a linearized Kramers-Kronig test to ensure that the rules of causality, linearity, stability and finiteness were kept. ${ }^{35}$ Equivalent circuit models were fitted to the impedance data using the LevenbergMarquardt complex non-linear least squares algorithm using software programmed in Python, which relies on parts of the scientific Python stack. $^{36-39}$

Parameter normalization.-The output parameters of the PET model fits have units normalized to the electrode thickness i.e. $R_{C T}^{\prime}[\Omega \cdot \mathrm{cm}], R_{i}^{\prime}[\Omega / \mathrm{cm}]$, and $Q^{\prime}\left[\mathrm{s}^{n} / \Omega \cdot \mathrm{cm}\right]$. In order to obtain the total values of these parameters for the electrode, one first must divide or multiply with the electrode thickness according to Eqs. 8a$8 \mathrm{~d}$. The effective capacitance $\left(\mathrm{C}_{\text {eff }}\right)$ of the pore wall (i.e. the carbon particles in the cathode) for the non-blocking situation was obtained using Eq. 8d, where the series resistance $\left(R_{s}\right)$ also was needed. To evaluate these parameters relative to each other, each variable was normalized to the active surface area of the porous carbon electrode (obtained from BET measurements and the mass of the carbon used in each electrode). Units are stated within the brackets.

$$
\begin{gathered}
R_{i}=R_{i}^{\prime} \cdot L=[\Omega] \\
R_{C T}=\frac{R_{C T}^{\prime}}{L}=[\Omega] \\
Q=Q^{\prime} \cdot L=\left[s^{n} / \Omega\right] \\
C_{e f f}=Q^{1 / n} \cdot\left(\frac{R_{s} \cdot R_{C T}}{R_{s}+R_{C T}}\right)^{\frac{1-n}{n}}=[F]
\end{gathered}
$$

For a flat planar electrode the effective capacitance denoted $\mathrm{C}_{\mathrm{dl}}$ was determined using Eq. 9 where $\mathrm{Q}_{0}$ was used to model the impedance of a blocking glassy-carbon disk electrode..$^{40,41}$

$$
C_{d l}=\left(Q_{0} \cdot R_{s}^{1-n}\right)^{1 / n}
$$

Microscopy.-The microstructure of the pristine XC72 cathodes was investigated by inspection of polished cross-sections in a Hitachi TM3000 tabletop scanning electron microscope (SEM), Figure S2. The polished cross-sections were prepared by vacuum embedding the electrodes in silicone rubber (Elastosil RT 675 A/B, Wacker Silicones); grounded using $\mathrm{SiC}$ paper and polished using 6, 3, and $1 \mu \mathrm{m}$ diamond paste. 


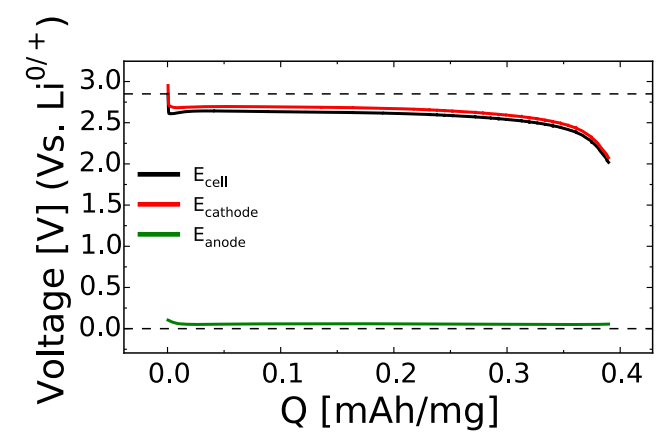

Figure 4. A galvanostatic discharge curve of $1 \mathrm{M}$ LiTFSI-DME operated under a constant pressure of 1060-1080 Torr discharged at $400 \mu \mathrm{A} / \mathrm{cm}^{2}$. The cell was maintained at constant pressure by keeping it connected to the inlet gas line. The black curve is the cell potential; the red and green curves are the cathode and anode potentials vs. the Li reference electrode, respectively. The two dotted lines correspond to the open circuit electrode potentials of the anode and cathode $\left(0 \mathrm{~V}\right.$ and $\left.\sim 2.85 \mathrm{~V}^{2}\right)$, respectively.

\section{Results}

Figure 4 illustrates a galvanostatic discharge curve of a $\mathrm{Li}-\mathrm{O}_{2}$ cell employing a Li metal anode, a XC72 cathode, and a 1 M LiTFSIDME electrolyte. The three curves represented in the figure illustrate the cell (two-terminal) potential, and the individual electrode potentials of the cathode and anode vs. the Li RE, respectively. It is clear that only a small part of the cell overpotential $(\sim 6 \mathrm{mV})$ originates from the Li anode, whereas the dominant part $(\sim 200 \mathrm{mV})$ originates from the electrochemical reactions on the cathode surface. Also, the sudden drop in potential (sudden-death) toward the end of discharge is purely due to the increase in the overpotential related to the cathode. Additionally, the Li anode contributes a slightly larger overpotential at the start of discharge before eventually reaching its lower steady state potential. This causes the initial dip and recovery in the overall cell voltage that is observed in many previous reports.

The cathode impedance in $\mathrm{O}_{2}$ during galvanostatic discharge.To investigate the impact on the impedance under conditions where either the surface- or the solution-based mechanisms is favored, three cells containing XC72 cathodes with $1 \mathrm{M}$ LiTFSI-DME, 0.3/0.7 M LiTFSI/LiNO3-DME, and $1 \mathrm{M}$ LiTFSI-DME with 1000 ppm $\mathrm{H}_{2} \mathrm{O}$, respectively, were investigated at $\mathrm{OCV}$ and under galvanostatic conditions. At OCV and in Ar, the impedance of the cathodes in these three cells was generally observed as being purely capacitive, with the exception of the $1000 \mathrm{ppm} \mathrm{H}_{2} \mathrm{O}$ containing cell also displaying a faradaic process (Figure S3). The two former cells also displayed a high frequency linear region, which is consistent with the impedance simulations (Figures $3 a-3 b$ ) performed using the PET model. The surface capacitance of flat disk glassy-carbon electrodes was investigated at similar conditions and similar electrolyte and was found to have similar capacitance $\left(6-8 \mu \mathrm{F} / \mathrm{cm}^{2}\right)$ as the surface capacitance of porous XC72 cathodes (Figure S4), which is in good agreement with previous reported surface capacitances of $5.3 \mu \mathrm{F} / \mathrm{cm}^{2}$ for Vulcan $\mathrm{XC72}$ in non-aqueous electrolytes.

To decrease the impact of the $\mathrm{O}_{2}$ concentration during galvanostatic operation, all cells were discharged at a partial pressure of $\mathrm{O}_{2}$ at 1000-1100 Torr. The following discharge capacities obtained were in increasing order: $1 \mathrm{M}$ LiTFSI $(\sim 0.4 \mathrm{mAh} / \mathrm{mg}), 0.3 / 0.7 \mathrm{M}$ LiTFSI $/ \mathrm{LiNO}_{3}$ cell $(\sim 1.5 \mathrm{mAh} / \mathrm{mg})$, and $1 \mathrm{M}$ LiTFSI with $1000 \mathrm{ppm}$ $\mathrm{H}_{2} \mathrm{O}(\sim 1.8 \mathrm{mAh} / \mathrm{mg})$ as illustrated in Figure 5a.

To evaluate the capacity limitations in these $\mathrm{Li}-\mathrm{O}_{2}$ batteries, it is essential to understand the impedance of the cathode under operation. The cathode impedance was measured throughout the discharge until $2 \mathrm{~V} \mathrm{vs} . \mathrm{Li}^{0 /+}$, but for practical reasons we present only the Nyquist and Bode plots for seven selected spectra, each of which were obtained during discharge in the regions labeled a-g in Figure 5b. The corre-
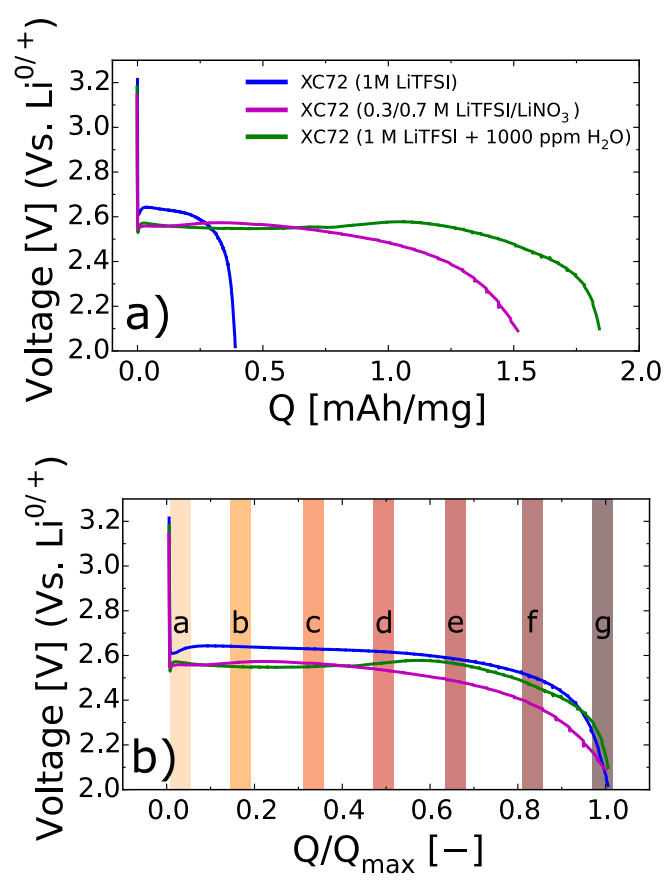

Figure 5. (a) Galvanostatic discharge curves for the three $\mathrm{XC72}$ cells with varying electrolyte at $400 \mu \mathrm{A} / \mathrm{cm}^{2}$ and (b) the equivalent normalized discharge curves. The $\mathrm{pO}_{2}$ was kept constant at 1000-1100 Torr throughout the discharges.

sponding Nyquist and Bode plots for the seven regions are presented in Figure 6 and S5, respectively.

In order to understand the contribution of each process to the cell performance, as well as to clarify the cause of the low- and high frequency processes, (Figure 6 and S5), the impedance of the three cells was fitted using the equivalent circuit: $-R_{s}-\left(R_{1} Q_{1}\right)-P E T_{\zeta=R_{2}}$, where $\left(R_{1} Q_{1}\right)$ is the high frequency (HF) semicircle observed at $10^{2}$, $10^{4} \mathrm{~Hz}$ while $(\mathrm{RQ})_{2}$ is the surface impedance $\left(\mathrm{R}_{\mathrm{CT}}^{\prime}\right.$ in parallel with $\left.\mathrm{Q}_{\mathrm{dl}}^{\prime}\right)$ in the PET model that corresponds to the low frequency (LF) process observed at $10^{-2}-10^{1} \mathrm{~Hz}$. The resulting parameters were normalized using Eqs. 8a-8d and each parameter is illustrated as a function of the normalized discharge capacity in Figure 7.

\section{Discussion}

Figure 5a shows a significant dependency between the discharge capacity and the composition of the electrolyte. In short, this is caused by a change in the $\mathrm{Li}_{2} \mathrm{O}_{2}$ formation mechanism. The increased capacity of $\mathrm{LiNO}_{3}$ containing cells was first reported by Burke et al. ${ }^{9}$ to be the consequence of an increased donor number of the electrolyte, as $\mathrm{Li}^{+}$ions are shielded by the $\mathrm{NO}_{3}{ }^{-}$counter-ion, thereby inducing an increased stability of $\mathrm{Li}^{+}$in solution, which shifts the equilibrium of $\mathrm{LiO}_{2}$ solvation and promotes the solution-based $\mathrm{Li}_{2} \mathrm{O}_{2}$ formation mechanism illustrated in (Figure $1 \mathrm{~b}$ ). The same solution mechanism enhancement has been reported for $\mathrm{H}_{2} \mathrm{O}$ containing cells, where $\mathrm{H}_{2} \mathrm{O}$ is postulated to behave as a strong Lewis Acid, thereby increasing the acceptor number of the electrolyte and stabilizing $\mathrm{O}_{2}{ }^{-}$, which again allows $\mathrm{Li}_{2} \mathrm{O}_{2}$ formation through the solution-based mechanism. ${ }^{8}$ In both cases, large toroid shaped $\mathrm{Li}_{2} \mathrm{O}_{2}$ deposits form, and on the basis of the impedance results discussed in sections below, we propose that toroids form through the solution-based mechanism in Figure 1B, in confirmation of previous reports on the growth mechanism of $\mathrm{Li}_{2} \mathrm{O}_{2}$ toroids. $^{5,6,8}$

We argue that the two activated electrochemical cathode processes detected when applying a current, i.e. the LF- and HF semicircles, observed in Figure 6 and S5, are mainly related to the formation of $\mathrm{Li}_{2} \mathrm{O}_{2}$ since (i) a $\sim 2.0-2.1 \mathrm{e}^{-} / \mathrm{O}_{2}$ reaction is observed from pressure 

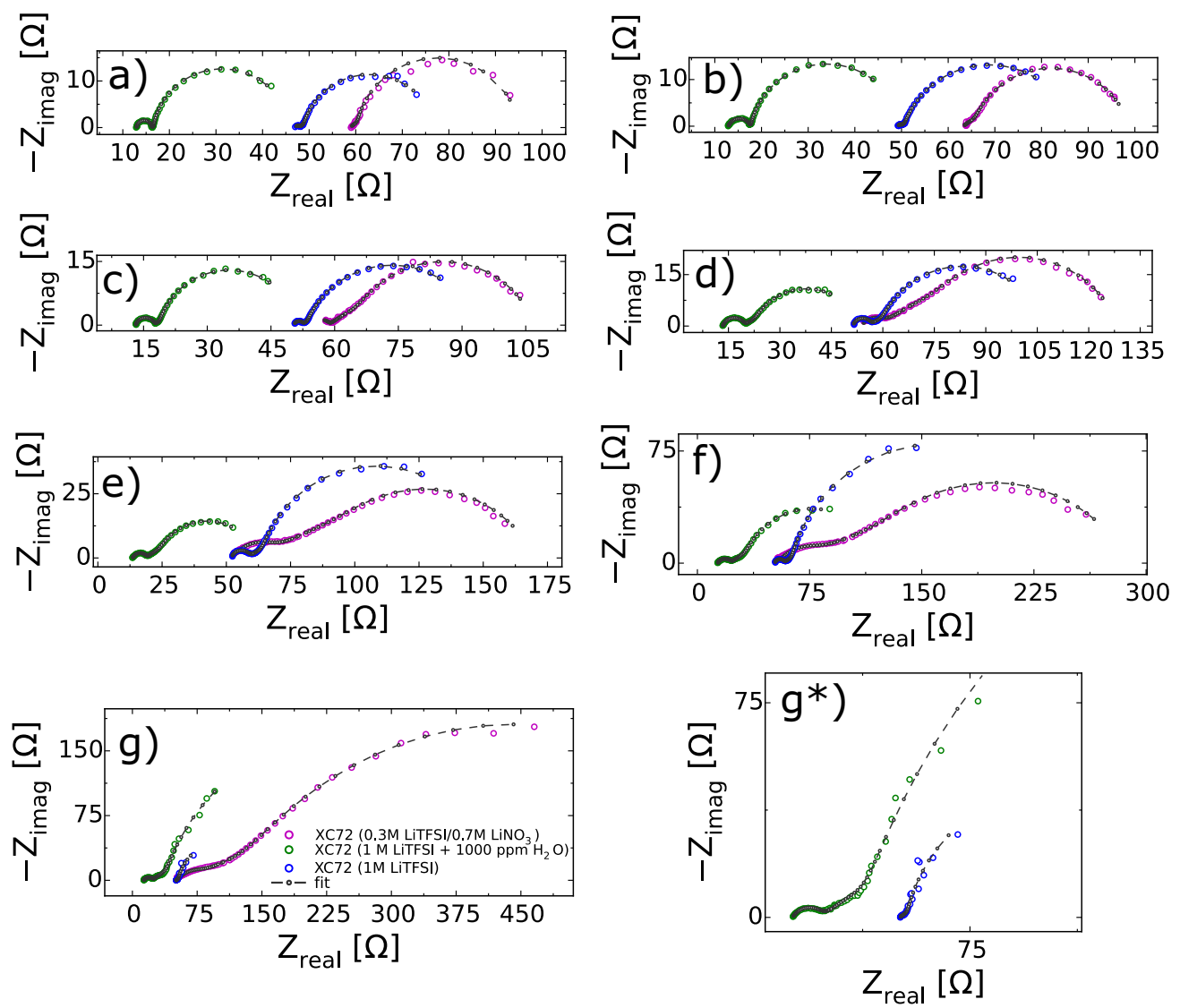

Figure 6. The progression of the galvanostatic impedance as a function of state-of-discharge: The regions a-g illustrate a specific state of normalized discharge capacity as is depicted in Figure 5, while $\mathrm{g}^{*}$ ) is a magnification of $\mathrm{g}$ ). The dashed lines illustrate the best equivalent circuit fit obtained.

measurements while discharging similar cells under a closed headspace filled with $\mathrm{O}_{2}$ (Figure S6-S8); (ii) multiple authors have also reported $\mathrm{Li}_{2} \mathrm{O}_{2}$ to be the main deposition product in these three solvents; $;^{5,8,42,43}$ and (iii) an impedance-study of $\mathrm{Li}-\mathrm{O}_{2}$, using two terminal Swagelok cells, observed the same LF semicircle in the same frequency range for $1 \mathrm{M}$ LiTFSI-DME containing cells. ${ }^{13}$

The cathode impedance under an $\mathrm{O}_{2}$ headspace in galvanostatic operation.-The impedance of the same cell measured at OCV and in galvanostatic mode is fundamentally different as illustrated by the difference between Figure 6 and S3C. At OCV under either Ar or $\mathrm{O}_{2}$, the impedance of the cathode exhibits behavior expected under nonfaradaic conditions, as no electrochemical reactions will occur with the $10 \mathrm{mV}$ amplitude given the moderate $\left(\sim 200 \mathrm{mV}^{44}\right)$ overpotentials for the $\mathrm{Li} / \mathrm{O}_{2}$ reaction. A description of the impedance at $\mathrm{OCV}$ is given in greater detail in the supplementary information. In galvanostatic mode, the impedance measures charge and mass transfer processes related to the active electrochemical reactions occurring at the cathode. In principle, we can therefore isolate capacitive and faradaic processes, allowing us to conclude that processes observed in Ar and at OCV, and measured with an amplitude of $10 \mathrm{mV}$ (Figure S3-S4) are not related to $\mathrm{Li}_{2} \mathrm{O}_{2}$ formation while the complex plane semicircles (Figure 6 and S9) that only are detected in galvanostatic mode under $\mathrm{O}_{2}$ atmosphere must be related to the surface reduction of $\mathrm{O}_{2}$ and the formation of $\mathrm{Li}_{2} \mathrm{O}_{2}$, as $\sim 2.0-2.1 \mathrm{e}^{-} / \mathrm{O}_{2}$ is observed at these conditions (Figure S6-S8)

The low frequency $(L F)$ semicircle.-The LF process observed in Figure 6 and S5 contain both the cathode surface/electrolyte interfacial charge transfer $\left(\mathrm{R}_{\mathrm{CT}}\right)$, the double-layer capacitance of the same interface $\left(\mathrm{C}_{\text {eff }}\right)$, and the proxy for the extent of pore clogging with the ionic resistance $\left(\mathrm{R}_{\mathrm{i}}\right)$ when modeled with the $\mathrm{R}_{\mathrm{s}}-\left(\mathrm{R}_{1} \mathrm{Q}_{1}\right)_{1}-\mathrm{PET}_{\zeta=\mathrm{RQ}_{2}}$ equivalent circuit. Using this model, one can understand from Figure 6 as the state-of-discharge increase, region a-f, the LF semicircle of the three cells in general become more skewed, which is a consequence of a change in the penetration depth (Eq. 4), i.e. a reflection of a change in the ratio between $R_{C T}$ and $R_{i}$ and was caused by an increase in $R_{i}$ as shown in Figure 7. Intuitively, this increase in $R_{i}$ is expected, as the formed $\mathrm{Li}_{2} \mathrm{O}_{2}$ is insoluble in $\mathrm{DME}^{2}$ and accumulates in the pores of the cathode, causing a decrease of the porosity.

Galvanostatic experiments conducted using flat planar disk GC electrodes in an $\mathrm{O}_{2}$ saturated electrolyte showed that a LF semicircle was the only electrochemical process detected, strongly indicating a kinetically controlled process under similar conditions (Figure S9). This observation adds support for the view that the surface impedance in the porous electrode can be modelled using a parallel RQ element. This LF semicircle was detected in a similar frequency range $\left(10^{-2}\right.$ $10^{1} \mathrm{~Hz}$ ) on the flat disk GC electrode as in the three cells with porous XC72 cathodes (Figure 6), which also agrees well with Højberg et al. ${ }^{13}$ We therefore suggest that the LF semicircle, both on the flat $\mathrm{GC}$ electrode, and in the porous XC72 cathodes, is related to the electrochemical reduction of $\mathrm{O}_{2}$ and the formation of $\mathrm{Li}_{2} \mathrm{O}_{2}$.

The high frequency (HF) semicircle.-The $0.3 / 0.7 \quad \mathrm{M}$ LiTFSI/LiNO ${ }_{3}$-based cell displayed an approximately four-fold discharge capacity increase while maintaining similar $\mathrm{Li}_{2} \mathrm{O}_{2}$ yields $(80$ $90 \%$ ) as the other two cells. ${ }^{9}$ Burke et al. ${ }^{9}$ ascribe the increase in capacity to the increase in the Lewis basicity of the electrolyte with added $\mathrm{LiNO}_{3}$, which results in the promotion of the solubility mechanism (Figure 1b). ${ }^{5,8,9,43,45}$ We would therefore expect that the resistance related to the HF semicircle, $\mathrm{R}_{1}$, which we have speculatively ascribed to a process associated with the solution-mechanism process, should increase in the $\mathrm{LiNO}_{3}$-bearing cell. We therefore compare the $1 \mathrm{M}$ LiTFSI $\left(0 \mathrm{M} \mathrm{LiNO}_{3}\right)$ and the $0.3 / 0.7 \mathrm{LiTFSI} / \mathrm{LiNO}_{3}$, which Burke 

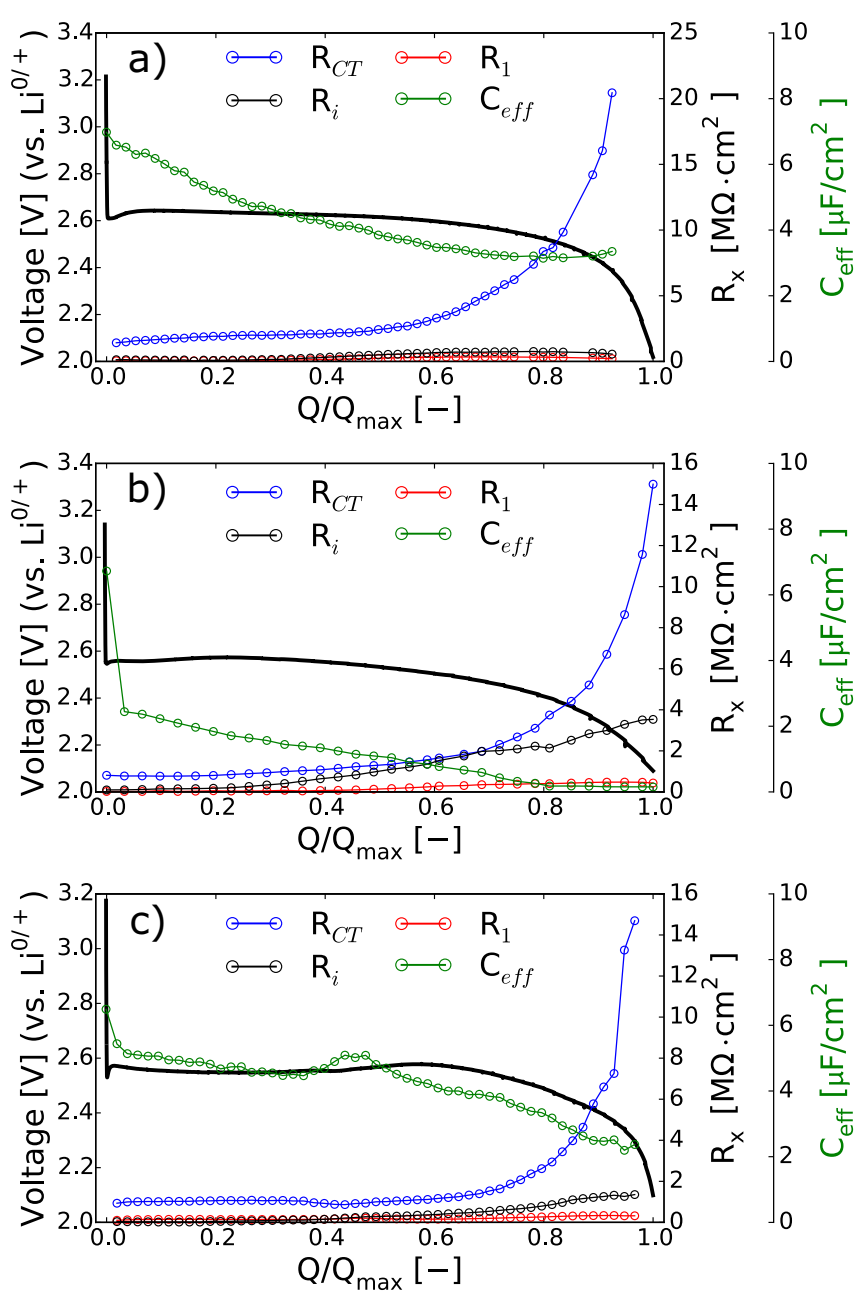

Figure 7. The resistances and the surface capacitance obtained by fitting the equivalent circuit model: $-\mathrm{R}_{\mathrm{S}}-\left(\mathrm{R}_{1} \mathrm{Q}_{1}\right)-\mathrm{PET}_{\zeta=\mathrm{RQ}_{2}}$ - to the three different systems: a) $1 \mathrm{M}$ LiTFSI-DME, b) $0.3 / 0.7 \mathrm{M} \mathrm{LiTFSI} / \mathrm{LiNO}_{3}$-DME, and c) $1 \mathrm{M} \mathrm{LiTFSI-}$ DME with $1000 \mathrm{ppm}_{2} \mathrm{O}$. The data presented originates exclusively from the impedance of the XC72 cathodes. $\mathrm{R}_{\mathrm{CT}}, \mathrm{R}_{\mathrm{i}}$, and $\mathrm{R}_{1}$ are the calculated charge transfer resistance, ionic resistance within the pores, and the charge transfer resistance related to the high frequency process, respectively. Only minor changes in impedance are observed at the anode and in the series resistance $\left(\mathrm{R}_{\mathrm{S}}\right)$ during discharge and have therefore been omitted.

et al. ${ }^{9}$ identified as the $\mathrm{LiTFSI} / \mathrm{LiNO}_{3}$ ratio that provided the largest capacity enhancement and as expected, the HF semicircle was detected to a much larger degree in the cell with $0.3 / 0.7 \mathrm{M} \mathrm{LiTFSI} / \mathrm{LiNO}_{3}$. This may indicate that the resistance associated with the HF semi-circle $\left(\mathrm{R}_{1}\right)$ is the faradaic charge transfer resistance of the solution-based mechanism, reaction $[\alpha]$ in Figure $1 \mathrm{~B}$, but as the HF semicircle also was detected throughout the discharge in the 1 M LiTFSI-DME containing cell (Figure 6) and in Ar and at OCV for this cell; this suggests otherwise. Another possibility is an activated process occurring at the stainless steel current collector when a solution-based mechanism is observed. Determining the associated capacitance of the HF process for the $\mathrm{NO}_{3}{ }^{-}$and $\mathrm{H}_{2} \mathrm{O}$ containing cells may help identify the surface at which the HF process originates. For example, normalization of the HF process to the projected area of the cathode current collector (stainless steel mesh and the perforated cell part of the EL-cell) results in capacitances of $9-39 \mu \mathrm{F} / \mathrm{cm}^{2}$ during discharge for the $\mathrm{H}_{2} \mathrm{O}$ and $\mathrm{NO}_{3}{ }^{-}$containing cells while values of $0.6-2.7 \mathrm{nF} / \mathrm{cm}^{2}$ are obtained by normalizing the same capacitance to the internal surface area of the cathode. Gaberscek et al. ${ }^{46}$ studied the impedance of current collectors in $\mathrm{LiFePO}_{4}$ cells and obtained surface capacitance of the current collectors/electrolyte interface in the order of $14-30 \mu \mathrm{F} / \mathrm{cm}^{2}$. Based on these observations, we tentatively ascribe the process to water redox at the current collector in the case of added water, and the appearance of a similar semi-circle when oxygen is present under conditions favoring the solution-based mechanism is likely caused by dissolved oxygen reacting. The HF semicircle was even observed in the $1 \mathrm{M}$ LiTFSI cell, where neither $\mathrm{H}_{2} \mathrm{O}$ nor $\mathrm{LiNO}_{3}$ should be available. We suspect minor water impurities likely contribute to the HF semicircle observed in the 1M LiTFSI cell and to this end, electrolytes were used as received and contained $\sim 25 \mathrm{ppm}_{2} \mathrm{O}$ as determined via Karl Fischer titration. Furthermore, although the cathodes used in this study were dried at $200^{\circ} \mathrm{C}$ in a glove box, their high surface area porosity could retain small amounts of water. We do note that the magnitude of the HF process is small in the 1M LiTFSI cell and diminishes with increasing state-of-discharge (Figure 6 and S5), which could be due to water consumption at the Li metal anode.

The capacity limiting processes.-The parameters obtained from fitting the equivalent circuit $-\mathrm{R}_{\mathrm{s}}-\left(\mathrm{R}_{1} \mathrm{Q}_{1}\right)-\mathrm{PET}_{\zeta=\mathrm{RQ}_{2}}$ - to the electrochemical impedance that describes the cell performance is illustrated as a function of the normalized discharge capacity in Figure 7 . The three cells can be compared until approx. $90 \%$ of the normalized discharge capacity, after which the Kramers-Kronig relations no longer were satisfied. The cause of the sudden-death for the three cells was therefore made by a comparison at $90 \%$ of the normalized discharge capacity. In general, it can be seen that $\mathrm{R}_{\mathrm{i}}$ increases more with the state-of-discharge when the solution-based mechanism is favored. We ascribe this increase in $\mathrm{R}_{\mathrm{i}}$ to the buildup of insulating, toroidal shaped, $\mathrm{Li}_{2} \mathrm{O}_{2}$ within the pores of the cathode. In the PET model, $\mathrm{R}_{\mathrm{CT}}$ increases with an increasing thickness of a conformal $\mathrm{Li}_{2} \mathrm{O}_{2}$ thin film on the surface of the electrode, as is observed in cells where the surface-based mechanism dominates. As a result, when comparing the three cells studied, $R_{i}$ is lowest and $R_{C T}$ the highest for the $1 \mathrm{M}$ LiTFSI-DME cell, as the surface-based mechanism is dominant in this electrolyte..$^{5,8,9,43,45,47}$

This is further demonstrated by the effective LF semicircle capacitance, determined using Eq. 8d, at sudden-death, which for the $1 \mathrm{M}$ LiTFSI-DME cell is $3.4 \mu \mathrm{F} / \mathrm{cm}^{2}$ (Figure 7). This corresponds to a theoretical $\mathrm{Li}_{2} \mathrm{O}_{2}$ thickness of $\sim 5.3 \mathrm{~nm}$, which was estimated using a dielectric constant of $\mathrm{Li}_{2} \mathrm{O}_{2}$ of $35^{48}$ and Eq. 10 .

$$
d=\frac{\varepsilon_{L i_{2} O_{2}} \cdot \varepsilon_{0}}{C_{e f f}}
$$

Where $\varepsilon_{0}$ is the permittivity of vacuum $\left(8.854 \times 10^{-14} \mathrm{~F} / \mathrm{cm}\right), \mathrm{d}$ is the $\mathrm{Li}_{2} \mathrm{O}_{2}$ thickness, and $\mathrm{C}$ is the surface capacitance in $\mathrm{F} / \mathrm{cm}^{2}$. The obtained theoretical thickness of $\sim 5.3 \mathrm{~nm}$ is in excellent agreement with studies that report $\mathrm{Li}_{2} \mathrm{O}_{2}$ thicknesses of 5-10 $\mathrm{nm}$ at sudden death on glassy-carbon electrodes in similar electrolytes. ${ }^{10,11}$ For the case where conformal deposition of dense $\mathrm{Li}_{2} \mathrm{O}_{2}$ can be expected $(1 \mathrm{M}$ LiTFSI in DME), the $\mathrm{Li}_{2} \mathrm{O}_{2}$ layer thickness calculated from capacitance linearly increases over most of the discharge (Figure S10a), whereas the calculated thickness increases nearly exponentially in the case of non-conformal deposition through the solution-based mechanism (Figure S10b-c). Furthermore, the $\mathrm{LiNO}_{3}$ and $\mathrm{H}_{2} \mathrm{O}$ containing cells obtained a $\mathrm{C}_{\text {eff }}$ of 0.15 and $2.37 \mu \mathrm{F} / \mathrm{cm}^{2}$ at sudden-death, resulting in theoretical $\mathrm{Li}_{2} \mathrm{O}_{2}$ thicknesses of 201.3 and $8.5 \mathrm{~nm}$ if the $\mathrm{Li}_{2} \mathrm{O}_{2}$ deposition is assumed to be a conformal, dense layer, which clearly does not apply under conditions where the solution-based mechanism is activated. The higher $\mathrm{R}_{\mathrm{i}}$ in these cells compared to the $1 \mathrm{M}$ LiTFSIDME cell reveals that $\mathrm{Li}_{2} \mathrm{O}_{2}$ instead has been deposited in the porous structure of these cathodes. Of note, the ratio between the experimentally found thickness (based on the change in capacitance) and the expected thickness (calculated from the passed charge) in Figure S10a was approximately 4 throughout discharge and the reason for this behavior is unclear. It is perhaps interesting to note the discrepancy between the experimentally found dielectric constant of $\mathrm{Li}_{2} \mathrm{O}_{2}$ $(\varepsilon=30-35)^{48,49}$ and that calculated for bulk $\mathrm{Li}_{2} \mathrm{O}_{2}$ using DFT $(\varepsilon=$ $7.5-12.5),{ }^{50}$ which also happens to differ by a factor of roughly 4 .

It is possible that the $\mathrm{O}_{2}$ gradients inside the pores during discharge are large enough to yield an appreciable diffusion resistance, which in 
this case would lead to an overestimation of the polarization resistance of the porous electrode. We have neglected oxygen diffusion losses in the model used here as we found it very difficult to obtain reliable impedance spectra below $10 \mathrm{mHz}$. However, the sudden-death in all three cells was still caused by the rate-limiting surface-based mechanism as $\mathrm{R}_{\mathrm{CT}}$ is the dominating cathode resistance at sudden-death for all three situations (Figure 7). This is in agreement with the planar electrode experiment, where the charge transport through $\mathrm{Li}_{2} \mathrm{O}_{2}$ no longer could support the applied electrochemical current, reflected in a greatly increasing $\mathrm{R}_{\mathrm{CT}}{ }^{10}$.

\section{Summary}

In this paper, we have performed electrochemical impedance spectroscopy on $\mathrm{Li}-\mathrm{O}_{2}$ cells and by using different electrolytes, the surfaceand solution-based mechanisms of $\mathrm{Li}_{2} \mathrm{O}_{2}$ growth were studied. Utilizing a 3-electrode configuration, it was possible to experimentally separate the electrochemical impedance into a cathodic and anodic contribution. The cathodic impedance displayed three electrochemical processes: a linear region at high frequency related to the porous structure of the cathode, a high-, and a low frequency process.

The low frequency process was not detected in Ar at OCV, but could be activated by applying a current in an $\mathrm{O}_{2}$ atmosphere. Through comparison with known literature and using similar experimental conditions on a flat planar glassy-carbon electrode, we conclude that this process is related to the surface reduction of $\mathrm{O}_{2}$ and the formation of $\mathrm{Li}_{2} \mathrm{O}_{2}$. The high frequency process was detected at both $\mathrm{Ar}, \mathrm{OCV}$, and while applying an electrochemical current. The process is possibly occurring at the current collector/electrolyte interface and was attributed to an additional redox reaction with either $\mathrm{H}_{2} \mathrm{O}$ or $\mathrm{NO}_{3}{ }^{-}$.

The porous electrode model was successfully applied to understand the impedance of the cathode, which made it possible to relate the ionic resistance to the increased formation of toroidal shaped $\mathrm{Li}_{2} \mathrm{O}_{2}$ as it forms in the pores of the cathode when the solution-based mechanism was activated. Nevertheless, charge transfer resistance was still found to be the primary origin of impedance in all cells, regardless of whether the surface or solution mechanism of $\mathrm{Li}_{2} \mathrm{O}_{2}$ formation was dominant clearly stating that the surface reduction of $\mathrm{O}_{2}$ is the capacity limiting process regardless of discharge mechanism in the studied electrolytes.

\section{Acknowledgments}

The authors gratefully acknowledge financial support from the ReLiable project (project No. 11-116792) funded by the Danish Council for Strategic Research, Program Commission on Sustainable Energy and Environment. The work at UC, Berkeley was supported in part by previous work performed through the Laboratory Directed Research and Development Program of Lawrence Berkeley National Laboratory under U.S. Department of Energy Contract No. DE-AC0205CH11231.

\section{References}

1. K. M. Abraham and Z. Jiang, J. Electrochem. Soc., 143, 1 (1996).

2. A. C. Luntz and B. D. McCloskey, Chem. Rev., 114, 11721 (2014).

3. C. O. Laoire, S. Mukerjee, K. M. Abraham, E. J. Plichta, and M. A. Hendrickson, J. Phys. Chem. C, 113, 20127 (2009).
4. C. O. Laoire, S. Mukerjee, K. M. Abraham, E. J. Plichta, and M. A. Hendrickson, $J$ Phys. Chem. C, 114, 9178 (2010).

5. L. Johnson et al., Nat. Chem., 6, 1091 (2014).

6. R. Black et al., J. Am. Chem. Soc., 134, 2902 (2012).

7. D. G. Kwabi et al., J. Phys. Chem. Lett., 5, 2850 (2014).

8. N. B. Aetukuri et al., Nat. Chem., 7, 50 (2015).

9. C. M. Burke, V. Pande, A. Khetan, V. Viswanathan, and B. D. McCloskey, Proc. Natl. Acad. Sci., 201505728 (2015).

10. K. B. Knudsen, A. C. Luntz, S. H. Jensen, T. Vegge, and J. Hjelm, J. Phys. Chem. C, 119, $28292(2015)$

11. A. C. Luntz et al., J. Phys. Chem. Lett., 4, 3494 (2013).

12. V. Viswanathan et al., J. Chem. Phys., 135, 214704 (2011).

13. J. Højberg et al., ACS Appl. Mater. Interfaces, 4039 (2015).

14. R. De Levie and P. Delahay, Advances in Electrochemistry and Electrochemical Engineering, p. 329, Wiley-Interscience, New York (1973).

15. C. Hitz and A. Lasia, J. Electroanal. Chem., 500, 213 (2001).

16. R. Jurczakowski, C. Hitz, and A. Lasia, J. Electroanal. Chem., 572, 355 (2004).

17. R. Jurczakowski, C. Hitz, and A. Lasia, J. Electroanal. Chem., 582, 85 (2005).

18. J. Nielsen, T. Klemens $\varnothing$, and P. Blennow, J. Power Sources, 219, 305 (2012).

19. J. Nielsen and J. Hjelm, Electrochimica Acta, 115, 31 (2014).

20. B. E. Conway, Electrochemical Supercapacitors, p. 337, Kluwer Academic/Plenum Publishers, New York, (1999).

21. R. Kötz and M. Carlen, Electrochimica Acta, 45, 2483 (2000).

22. E. Barsoukov, J. H. Kim, J. H. Kim, C. O. Yoon, and H. Lee, Solid State Ion., 116, 249 (1999).

23. A. Lundqvist and G. Lindbergh, Electrochimica Acta, 44, 2523 (1999).

24. M. Maja, C. Orecchia, M. Strano, P. Tosco, and M. Vanni, Electrochimica Acta, 46 423 (2000).

25. R. Scipioni et al., ECS Trans., 69, 71 (2015).

26. J. Bisquert et al., J. Phys. Chem. B, 104, 2287 (2000).

27. F. Fabregat-Santiago, J. Bisquert, G. Garcia-Belmonte, G. Boschloo, and A. Hagfeldt, Sol. Energy Mater. Sol. Cells, 87, 117 (2005).

28. J. Bisquert et al., Electrochem. Commun., 2, 601 (2000)

29. J. Bisquert, G. Garcia-Belmonte, F. Fabregat-Santiago, and A. Compte, Electrochem. Commun., 1, 429 (1999).

30. A. Lasia, Electrochemical Impedance Spectroscopy and its Applications, Springer, (2014) .

31. J. Bisquert et al., J. Phys. Chem. B, 104, 2287 (2000).

32. R. de Levie, Electrochimica Acta, 9, 1231 (1964)

33. F. Mansfeld, S. Lin, Y. C. Chen, and H. Shih, J. Electrochem. Soc., 135, 906 (1988).

34. D. T. Sawyer, A. Sobkowiak, J. L. Roberts, and D. T. Sawyer, Electrochemistry for chemists, Wiley, (1995).

35. B. A. Boukamp, J. Electrochem. Soc., 142, 1885 (1995).

36. J. D. Hunter, Comput. Sci. Eng., 9, 90 (2007).

37. J. O. Oliphant P. Peterson et al., 2001.

38. S. van der Walt, S. C. Colbert, and G. Varoquaux, Comput. Sci. Eng., 13, 22 (2011).

39. C. Graves, RAVDAV Data Analysis Software, Version 0.9.7; Technical University of Denmark: Roskilde, Denmark, 2012.

40. G. J. Brug, A. L. G. van den Eeden, M. Sluyters-Rehbach, and J. H. Sluyters, J. Electroanal. Chem. Interfacial Electrochem., 176, 275 (1984).

41. B. Hirschorn, Electrochimica Acta, 55, 6218 (2010).

42. B. D. McCloskey et al., J. Phys. Chem. Lett., 4, 2989 (2013).

43. K. U. Schwenke, M. Metzger, T. Restle, M. Piana, and H. A. Gasteiger, J. Elec trochem. Soc., 162, A573 (2015).

44. J. S. Hummelshøj, A. C. Luntz, and J. K. Nørskov, J. Chem. Phys., 138, 34703 (2013).

45. A. Khetan, A. Luntz, and V. Viswanathan, J. Phys. Chem. Lett., 6, 1254 (2015).

46. M. Gaberscek, J. Moskon, B. Erjavec, R. Dominko, and J. Jamnik, Electrochem Solid-State Lett., 11, A170 (2008).

47. I. Gunasekara, S. Mukerjee, E. J. Plichta, M. A. Hendrickson, and K. M. Abraham, J. Electrochem. Soc., 162, A1055 (2015).

48. O. Gerbig, R. Merkle, and J. Maier, Adv. Mater, 25, 3129 (2013).

49. A. Dunst, V. Epp, I. Hanzu, S. Freunberger, and M. Wilkening, Energy Environ. Sci., 7, 2739 (2014)

50. M. D. Radin and D. J. Siegel, Energy Environ. Sci., 6, 2370 (2013). 